\title{
The Structure of Interpretations in Family Therapy: A Video-Enhanced Exploration*
}

STEVEN J. TRIERWEILER, Ph.D.† DONNA K. NAGATA, Ph.D.‡ JOSETTE V. BANKS, M.A.

A method for assessing the structure of interpretations of family therapy events is described. Family sessions were videotaped; each participant then independently reviewed the tape, stopping it to indicateany significant events and describing the importance of each identified sequence Qualitative approaches to anaIyzing the stop points are described, using data from six families and their therapist. This combination of direct session experience and reflective interpretation provides a much-need ed perspectiveon themeaning of sessions and psychotherapeutic interaction. Research and clinical implications for scientifically examining the structure

* Thanks to Debra Helinski for assistance in data reduction and management. This research was supported by the Department of Psychology at Smith College, and the University of Michigan. We are particularly indebted to the therapists and families who participated in this work.

† Steven J. Trierweiler, Ph.D., is an Associate Professor of Psychology in the Department of Psychology, and an Associate Research Scientist at the Institute for Social Research. Address correspondence to Dr. Trierweiler, Department of Psychology, University of Michigan, East Hall, 525 East University, Ann Arbor MI 48109-1109; e-mail: stevtri@ umich.edu.

‡ Donna K. Nagata, Ph.D., Associate Professor in the Department of Psychology, and J osette V. Banks, M.A., Doctoral Candidate in Clinical Psychology in the Department of Psychology, are both affiliated with the Department of Psychology, University of Michigan, Ann Arbor MI. of shared interpretations in family therapy are discussed.

Fam Proc 39:189-205, 2000

$\prod \mathrm{H}$ HE complex interactions within family therapy offer rich data but also pose significant methodological challenges. As a result, the micro-examination of family therapy process has become increasingly important (Gurman, Kniskern, \& Pinsof, 1986; Pinsof, 1981, 1986, 1988, 1989; Rice \& Greenberg, 1984). This focus has led researchers to move from gl obal measures to a variety of more "microchange" assessments of therapeutic efficacy (Pinsof, 1986). Some have coded behavioral events, both verbal and nonverbal, to describe the therapy process (Alexander, Barton, Schiavo, \& Parsons, 1976; Postner, Guttman, Sigal, et al., 1971); others have evaluated client self-reports concerning the alliance between the therapist and family members (Pinsof \& Catherall, 1986).

One basic question under investigation is the degree to which there is convergence among therapy participants in their interpretations of therapeutic process (Pruchno, 1993a). Although therapists might accept their view of events in a family session as definitive, there is evidence against this belief (Pruchno, 1993b). 
As Bavelas (1984) has noted: "It is unlikely, even in clinical settings, that the same information is rel evant to the family and to the therapist (p. 339)." Gurman et al. (1986, as cited in Pinsof, 1989) pointed out that within thefamily therapy perspective, thereis no single, independent, objective reality (p. 568), and Heatherington, Friedlander, J ohnson, et al. (1998) identified individual differences among participants even in their construal of the meaning of family therapy. Research has begun to address this problem. However, most studies rely on retrospective, and usually nonspecific, post-therapy questionnaire evaluations. As such, we know little about how these evaluations/perceptions map onto specific moments in the time stream of a therapy session. Such specificity is critical to any attempts to take context into account when evaluating therapy and family interactions (Bavelas, 1984; Heatherington, 1989; Kiesler, 1986; Pinsof, 1986).

This article presents a methodology designed to explore the structure of the multiple interpretation of events existing among family participants and their therapist within a therapy session. The methodol ogy, which we call, video reconnaissance, uses video as an aid to participants' retrospective exploration of their own process in the session. The idea of "reconnaissance," which is an aspect of psychiatric interviewing as discussed by Sullivan (1954), involves looking back over some extant information domain to gather data relevant to a particular purpose. This terminology is consistent with our primary goal of collecting and arranging the information resulting from the multiple perspectives existing in the therapy session so as to reveal the interpretive structure(s) of the sessions. In this procedure, family therapy sessions are video recorded and then each family member and their therapist returns to the clinic independently to review the videotaped ses- sion. During the video reconnaissance interview, participants are asked to stop the tape any time they feel something significant had occurred, from their own perspective. As they do so, theinterviewer records the time code from thetape and asks them to describe the significance of the identified moment in their own words. Comments during the review session areaudiotaped and transcribed. The resulting information is then: (a) treated as a combination of direct review and the retrospective interpretation typically found in a participant's memories, and (b) translated, summarized, and arranged in ways that allow within and between participant comparisons to address clinical and research questions that might be raised about session phenomena (e.g., Why was a participant particularly quiet at a particular point in the session?).

The information yield of video reconnaissance is intuitively appealing, inherently interesting, and a promising means for deepening our understanding of family therapy content and process. Nonetheless, as qualitative data, it is al so quite complex and difficult to grasp in its totality without considerable data reduction and analysis (Miles \& Huberman, 1994). Our objective in this artide is to demonstratethe scientific and dinical promise of this approach and to suggest some data-organizing strategies for conceptualizing and analyzing interpretation in family sessions. Video reconnaissance represents material that is highly relevant to therapy process, but is often inaccessible. Such material needs to be accounted for in theory and research if the family therapy field is to advance in a scientifically grounded fashion.

\section{Background}

Videotape has been used to provide feedback to individual adults (Alger, 1969), groups (Hogan \& Alger, 1969), couples (Alger \& Hogan, 1969; Fichten, 1984; Halford \& Sanders, 1988), families (Alger \& Hogan, 1969; Alger, 1976), and children 
(Sanders \& Dadds, 1992). As a tool for retrospective examination of individual behavior and interpersonal interactions, it also has played a major role in therapist training, and in the study of psychotherapy process. Over 30 years ago, Kagan, Krathwohl, and Miller (1963) described a video-stimulated recall procedure for counseling sessions, which they called Interpersonal Process Recall (IPR). The participant is asked to remember and describe experiences associated with various conversations identified in the video (Elliott, 1986). IPR has been used to enhance efficacy of therapy and to createa variety of simulations for use in counsel or training (e.g., Kagan \& Kagan, 1990; Kagan \& Schauble, 1969). Elliott (1986) noted that this basic approach has been "discovered" by a great variety of researchers interested in examining experience and thought process in psychotherapeutic interactions (e.g., Knudson, Sommers, \& Golding, 1980; Meichenbaum \& Butler, 1980). Bloom (1954) used an early, and highly structured version of the approach in a classroom setting, and Alger (1969, 1976) identified numerous therapeutic applications for videoplayback. More recently, Elliott and his colleagues (Elliott, 1986; Llewelyn, Elliott, Shapiro, et al., 1988) have used IPR to examine psychotherapy process and, in particular, "good moments" in the stream of psychotherapy sessions. This research team has incorporated the IPR approach into a broader qualitative research framework for analyzing therapy process which they call Comprehensive Process Analysis (Elliott, Shapiro, Firth-Cozens, \& Stiles, 1994). It involves extensive interpretive analysis of session moments in videos, as identified by clients and researchers, to address particular scientific and clinical questions. For example, Elliott et al. (1994) used this detailed grounded framework to examine insight events in two different types of therapeutic intervention.

\section{Video Reconnaissance Method}

Like the many other researchers Elliott (1986) described, we were not cognizant of this diverse body of work when we designed our procedure for usage in the context of family therapy sessions. Video reconnaissance is highly related to these earlier studies and should be considered one of numerous possibleperspectives on the use of video to enhance research and therapeutic practice. However, our approach is unique in its focus on the nature of participant interpretations of what is happening in therapy and how these interpretations coexist within the ecology of a session. This focus leads us to treat the information yielded by the procedure differently than previous researchers. There are a number of theoretical and procedural divergences. First, the primary focus in video reconnaissance is on how events occurring in the therapy are perceived and interpreted. No particular events (such as "good moments" or change events) are specified, nor is the idea of event defined (e.g., as a momentary phenomenon, a change event, or in any other way) apart from something that the participants designateas important from their own perspective. Second, both family members and the therapists participate in equivalent fashion. Third, participants spontaneously identify significant events as they review their session videotape; there is no prior discussion of what was important to participants before they view the tape. In keeping with our focus on participant interpretation of events during sessions, the reconnaissance interviewer does not stop the tape for the participants apart from a 10-minute "check-in" if no stop has been made (seeWatson \& Rennie, 1994). This contrasts with the original IPR technique of Kagan, and several of its successors, where researchers emphasized a variety of specific research objectives (such as identifying the efficacy of particular counselor interventions) and the research interviewer identified points in the material for examination by a participant. Fourth, we are concerned 
with the systemic aspects of the interaction and, therefore, have designed an approach that illuminates convergenceand divergence in thevarious interpretations of thematerial that participants produce.

To illustrate the value of video reconnaissance, we present results from a multiplecase study. Because the objective here is to introduce a perspective on the naturalistic examination of family session interpretation, as well as to offer some of our research findings, we present commentary along with our discussion of the results of the study. Specifically, we will show how the video reconnaissance interview operationalizes the multiple experiences, descriptions, and explanations of events that always exist in family sessions. In so doing, it becomes apparent that some of the most interesting things about sessions may lie in what is unsaid. Video reconnaissance provides an operational model and a standard for considering how clinicians might deepen their exploration of this material during and after sessions.

\section{METHOD}

\section{Participants}

Participants in the study included six families and their therapists all of whom were in ongoing family therapy at a community mental health center. Each family had one child/adolescent who was the identified patient. There were no siblings in the sample. Three of the families included both a biological mother and father, two were families with singleparent mothers, and one included the child's guardian and grandmother. The children's ages ranged from 9 to 17 years, with a mean of 14.7. There were two female and four male children. The therapistsone male psychol ogist and onefemal esocial worker-were experienced clinicians. Five of the families participating in the study were in therapy with the male, and one with the female clinician. All families were in the early-middle to middle stages of their treatment, with number of sessions ranging between four and nine-plus with the mode being six.

The study involved a convenience sample of families recruited through contacts with their therapists. Information was provided regarding the research, its procedures, and the investigators. Families volunteered to participate. A small amount of money $(\$ 15)$ was paid to each family member as compensation for the extra time required to participate in the study. Therapists did not receive monetary compensation, but did receive summary feedback about the reconnaissance material consistent with the limits of confidentiality arranged for the reconnaissance interviews (see below). The project was reviewed and approved by a standard human subjects review board and by the therapists and director of the clinical facility in which the data were collected.

\section{Procedure}

Prior to videorecording, each family member independently signed a consent form that described the study procedures, indicated that identifying information would be removed from presentation of the results, indicated that the material would be used only for research purposes, and assured that their participation was voluntary and they could withdraw at any time. Additionally, they were offered the opportunity to have their review comments shared with their clinician for its potential use in their treatment if they so desired. All participants chose in writing to have their comments shared with their clinician. A single family therapy session was videorecorded. Following the taping, each family member and the therapist individually returned within 10 days for the video reconnaissance interview. During the video reconnaissance, participants viewed the videotape of the original session accompanied by a research interviewer (Nagata). As they watched, they paused the tape using a 
remote control device whenever they felt an important event occurred. If 10 minutes had elapsed, the interviewer stopped the tape to ask if anything significant had happened in the preceding time period. This procedure primarily was used to insure that the participant understood the task and to encourage invol vement if there was a slow start; but it was required only three times in the entire data collection. At each stop, the interviewer asked the participant to describe what it was about that portion of the tape that seemed significant. These responses were audiotaped. Participants agreed not to discuss their video review with others until all research sessions had been completed.

Videotapes of the sessions and audiotapes and notes from the reconnaissance interviews were transcribed and entered into a database (Filemaker Pro) for organization and analysis. The database was structured around each change in speaker during the therapy session, recorded to the nearest second.

\section{RESULTS}

\section{Identifying Stop-Point Locations}

The basic structure of the independent interpretations made by participants in the video reconnaissance interviews can be illustrated with a diagram of the temporal locations of the stop points. To construct such a diagram, it was necessary to define agreement in relation to a time unit. We reasoned that agreement at the level of the exact second was too conservative, even though this type of agreement did occur on occasion in this study. Conversations about particular topics often spanned several minutes, making 5-minute reference units reasonable. However, 5-minute units were a significant proportion of each session, which lasted about 50 minutes, thereby inflating consensus. Our compromise was 2-minute units, which captured reasonable agreement without substantially inflating it.

The Figure (see below) presents the stoppoint display for an illustrativecase. In this report, we do not assume that our sample is representative of all family sessions within or between family/therapist pairings, nor that any particular result will be generalizable to all sessions. Rather, our objective is to show how interpretive structure in specific clinical situations can be examined. The results suggest generalizable properties that could be assessed in any clinical situation (see Stricker \& Trierweiler, 1995; Trierweiler \& Stricker, 1998).

The Figure shows the temporal organization of the retrospective interpretations across an entire family session. The thick

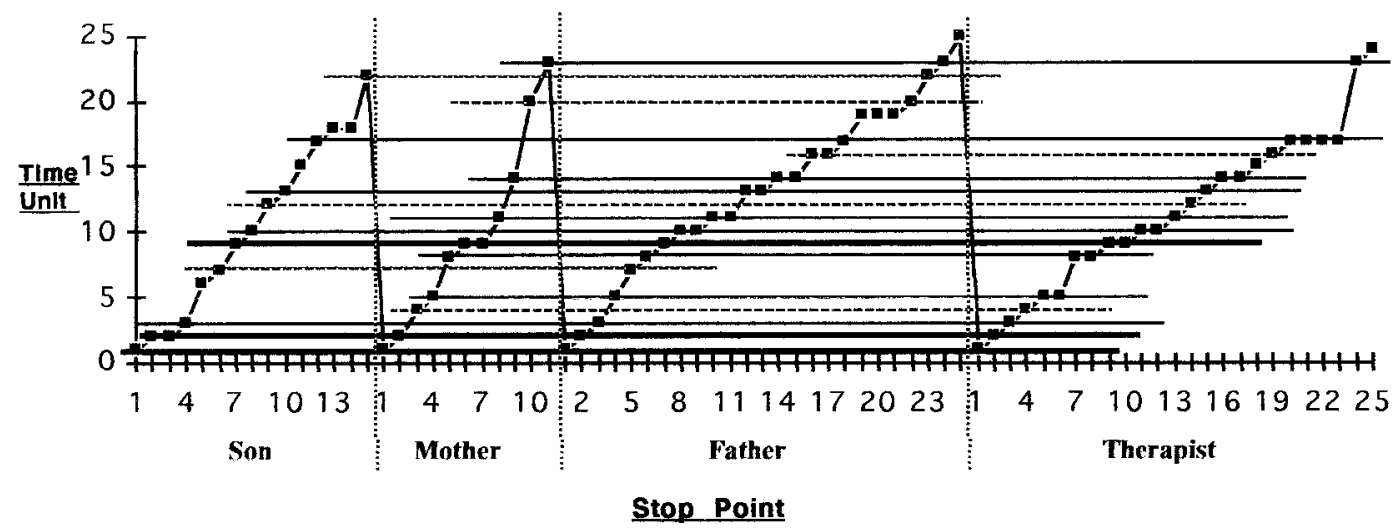

FIGURE. Stop-point display for the therapy session of Family Three.

Fam. Proc., Vol. 39, Summer, 2000 
lines indicate each 2-minute time point when all participants agreed that a significant event had occurred and offered their commentary. Thin, solid lines represent points of three-person agreement, where applicable, and broken lines represent twoperson subgroup agreement. For ease of interpretation, we arranged the displays so that the child/adolescent is shown on the extreme left and the therapist on the extreme right. Parents were placed in the order: mother, then father, then therapist. When applicable, other adults were placed to the left of the parents.

Several qualities of the stop-point locations that were typical in our sample of family sessions are illustrated in the Figure. Often there were multiple stops early in the session suggesting that both families and therapists saw early parts of session as important. Children tended to stop the tape less than the most active parent and the therapist. As a result, full consensus, which required the child's involvement, was relatively rare. Yet, it also was rare in this sample for a child to stop the tape in isolation from independently obtained designations by other participants. Indeed, it was unusual for any participant to identify an event in isolation from others. The stoppoint data also revealed session patterns commonly observed by family therapists. For example: There always was a very active parent (at least one). Complementing the rarity of the stop designations by children, active parents stopped the tape at $50 \%$ or more of the possible time units. This high stop-frequency increased the probability of a match with a stop point identified by the child. Additionally, inspection of the therapy session transcripts showed that children's stops were particularly coordinated with major affective moments in the sessions and, therefore, these times tended to elicit consensus (indeed there were particularly powerful times where the stops were virtually within one second of one another for four people).
The stop-point displays also showed that therapists tended to stop the tape at the same session segments as the parents/ guardians, but rarely converged with the children's stop points. Participant comments at the stop points often indicated they noticed the influence of the therapist in facilitating particular session events, even though no verbal acknowledgment of this observation occurred during the therapy itself. This influence was sometimes seen positively, as in letting something hidden come to light, but at other times negatively, as in doing something that made a participant uncomfortable, such as prodding a child to talk about some aspect of his behavior that he or she did not like or found embarrassing.

\section{Content Reference Models}

In addition to identifying similarities on locations in the tapes attended to by participants, one can examine the content both of the family sessions during the identified stop times and of the individual reconnaissance interviews concerning that material. We refer to the combination of transcript and reconnaissance commentary by each participant as the content reference model for the session. The content reference model of a session is designed to show actual interpretive complexity of session contents in a reasonably comprehensible format, thus setting the foundation for further analysis. The Appendix shows portions of a typical content reference model taken from one of the family sessions (Family Three) used in the study. Family Three, which included a mother, father and adolescent son, entered therapy to address the son's school absenteeism. Their material shows the rich structure of interpretations of family members and the therapist around a relatively common parent-teen conflict about school performanceand attendance. The content reference material in the Appendix has been reduced to summarize the comments made by participants 
(see Endnote, p. 203). Because of space limitations, we have presented excerpts from the content reference model of only Family Three. Full models for this and other families are available on request. We will present some of our findings on the nature of contents mentioned and on a typology of forms of consensus in a future report.

Several general qualities of the video reconnaissance material are noteworthy:

1. Because the material is in the participants' own language, this commentary opens up many avenues for additional and more focused inquiry into the meaning of a particular session for each individual.

2. The material represents a type of commentary similar to thethinking-aloud procedures found in cognitive experiments (e.g., Ericsson \& Simon, 1993), but it is actually a more grounded and comprehensive version of what is typically obtained only from memory in psychotherapeutic interactions. On occasion, the external perspective assodated with viewing the videotape provoked completely new information useful in a therapeutic context, such as a response to seeing something not previously noticed about oneself or others. For example, at TimeFive (see the Appendix), the father noted with surprise how unpleasant he looked, when his memory of the session was that he was trying to be pleasant and easygoing.

3. In effect, the content reference model of a session directly represents portions of an ongoing post hoc reflective process. This process exists, in principle, for any interpersonal experience, but it rarely is realized in any comprehensive fashion (see Trierweiler \& Donovan, 1994; Trierweiler \& Stricker, 1998). Therapists and clients must draw on their own memories of events to access interpersonal and systems phenomena, usually depending solely on their own experience and perspective. In contrast to this memorybound material, video reconnaissance and the resulting content reference model for a session providericher, more extensive reflective views of all therapy participants. As such, the procedure establishes one criterion against which to evaluate any understanding of interactions in a session. Of course, the content reference models from video reconnaissance are, themselves, incomplete; they are only partial representations of the latent models that might emerge over several assessments, or as participants gain new insights into family interactions. However, compared to memory alone, even single session models such as those obtained in this study have great advantage in revealing material that would remain in the shadows unless somehow otherwise elicited (see Trierweiler \& Donovan, 1994).

Inspection of the model in the Appendix suggests some possible analytic implications of thestructure of the video reconnaissance material. In perusing the columns of the model, the individual's perspective becomes apparent even without referring to the session transcript. The columns reveal whether the stop was executed for a specific or more general observation during a particular portion of the session, who is being talked about, and how the individual feels about the person or event described. The rows of the model shed light on theintersection of perspectives: points of agreement in stopping the tape and the rel evant commentary can be compared across participants. Because each row entry was independently obtained, a row reflects the coherence of the family and therapeutic system and reveals points of consistency in thesession interpretations. Different participants sometimes talked about the same session material at the same stop point, sometimes different material.

Importantly from a clinical perspective, disagreements-or what seems to be misunderstandings or misinterpretations-become most obvious in reading across successive rows of a content reference model. Time One (Appendix), for example, shows how all members of Family Three focused

Fam. Proc., Vol. 39, Summer, 2000 
on the same content issue (the lack of talk by the son in response to the mother's introduction of a school problem). Yet, different perspectives on this phenomenon were made explicit in the reconnaissance material: The child said he should have been talking more; mother described how this segment was typical of family interactions at home and noticed that she talked too much; father expressed his disappointment that his son was not saying more and attributed this reticence to the son's lack of interest or effort; and therapist saw this segment as significant in that it typified the mother/son interaction in this family.

A particularly interesting example of different interpretations of the significance of a specific therapy segment was found in the session of another family (not shown in the Appendix), consisting of a teenage daughter, her mother, and the therapist. All therapy participants stopped the reviewed the videotape at a point when the daughter's birthday celebration was being discussed. The daughter reported that this discussion had bothered her because she disliked receiving attention and compliments and did not enjoy talking about it with the therapist, whom she perceived as having brought the topic up. In her reconnaissance interview, her mother described this same segment differently. From the mother's perspective, her daughter was acting nonchalant about something that she really liked, and the mother was upset that the girl was not more expressive. The therapist, meanwhile, viewed the same segment as exemplifying a rare, positive interaction between the mother and daughter.

The rows for successive time units in a content reference model reveal whether material from the session transcript-or hidden material revealed only in reconnaissance interviews with other participantswas identified by particular individuals. For example, in the reconnaissance interview, participants often commented upon specific issues that they had exhibited no apparent awareness of during the session. Although this was true for all participants, it was particularly true for the therapist, who seems to have had a very complex and thorough conceptualization of a situation but who showed little behavioral evidence of this in the course of the interaction. This is exemplified at Time Eight of the Appendix, when the therapist revealed his thoughts about the father's ambivalence about whether he needs to continue being a father to his son. Yet, in the video transcript, the therapist focused on asking brief, clarifying questions to explore how well the son had heard his mother's description of his problems.

Finally, entries viewed diagonally across rows of a content reference model reveal descriptive qualities of antecedent-consequent process in the dyadic or highersystemic interactions taking place over the course of the therapy session. I nasmuch as reconnaissance material involves summary statements about general issues in the family and statements about what is going on from a participant's perspective, it can reveal thematic or cyclic phenomena that would be difficult to discern simply with a transcript or by participating as a therapist in a session (although this is undoubtedly the kind of material described by many experienced therapists when they refer to process). For example, in Family Three's Time One (Appendix) the father, in his reconnaissance session, commented on how the son was not participating in the session early on. Later, the father remarked that he was glad to see the son stick up for himself in a brief interaction. Still later, the father wondered if he and the mother had let the son finish expressing his viewpoint. In the next 2 minutes, the son commented on how the father seemed to have backed down rather than sticking up for his position. This sequence - of father wondering if son had finished and son seeing father back down-nicely illustrates how "standing up for one's position" might be a subtle, but 
unrecognized, issue for the males in this family, and how the father's positive attempts to let his son talk might have been negatively interpreted by the son as the father's inability to stand up for himself. This hypothesis is consistent with other information existing in the therapy about their previous relationship as it pertained to the presenting problem of getting son to go to school.

\section{I dentifying Consensus}

One striking aspect of the reconnaissance material is the degree to which particular points in the session were identified as important by all of the therapy participants (see Figure). Often these points were affectively loaded during the sessi on and occasionally during the reconnaissance interview as well. Because consensus points were independently identified in the reconnaissance interview, they powerfully illustrate how multiple perspectives and agendas among family members converged on particular therapy events.

\section{Consensus Points}

E mbedded within the Appendix are several examples of video reconnaissance material from consensus points for Family Three. These points illustrate several of the types of retrospectively derived content consensus that existed in sessions. Time One, as described earlier, shows how each family member targeted the same early moment in the therapy session when the son was not talking, yet they provided very different perspectives on the significance of that moment.

The second consensus location for this family occurred within the next 2 minute segment (Time Two) when the school problem discussion continued and showed both partial agreement and differing interpretations even though the stimulus was generally agreed upon-namely, the father's remarks in the session about the school problem. Several previously hidden perspec- tives were revealed as participants commented on the discussion. The video transcript suggests that father was wondering if he and mother had overemphasized the school issue. In the reconnaissance, the father expressed disappointment with his son more directly than hehad in thetherapy session, thereby raising a question about how his lack of direct expression of feelings and wishes might have been relevant to the treatment. Mother also wondered about the overemphasis on school but, in the reconnaissance, expressed her interpretation that the father was ready to give up. This assertion may have originated in some private conversation she and father had had about this issue, or it simply may reflect an interpretation on her part. The son's reconnaissance commentary revealed his sense that his father was doubting him and incorrectly interpreting the son's own view. During the same point in the session, the therapist's reconnaissance material raised the possibility that father was minimizing and trying to back away from the problem. Note how any or all these interpretations may have been correct at some level, but together they lend considerable complexity to a sequence in the treatment that might otherwise have seemed unremarkable.

The third and last consensus point for this family (Time Nine) offers an extremely interesting meta-perspective on a confusing section of the transcript where son and father seemed to be disagreeing about the son being late for school. In the session transcript, the father expressed disbelief that the son made it to class on time in the morning. The son's reconnaissance shows that son would have liked parental nagging to stop. Mother said directly that she did not believe that son wanted to stay in school and that there was a problem with misunderstandings in the family. What might she have meant by this? Father was glad to see son stand up for himself against father in the session, and wondered if they (the parents) had ever let son get his point across. The therapist re-

Fam. Proc., Vol. 39, Summer, 2000 
ported seeing confrontation but no followthrough from father, and then openly expressed his own confusion. This confusion and misunderstanding, reflected both in the therapist's review comments and in the reconnaissance material in general, may have represented a microcosm of the family discord. Also interesting was the father's positive attention to the son being assertive with him, an attitude that-like numerous other comments in the reconnaissanceinterviewswas not discernible in the session material itself, and may point to a special connection between these two family members.

\section{Subconsensus Points}

Also important were points of subconsensus where a subgroup commented on some aspect of the session. Usually this subgroup consisted of the therapist and the most active parent, but at times involved others as well. These points can show how two individuals understand or sympathize with one another. Also, they can show evidence of triangulation not apparent in session, whereby a third individual, who often was the therapist, might be excluded from an important implicit conversation. For example, at one point late in the session for Family Three (not shown in the Appendix), where the discussion was about the son agreeing to stay in school, both parents independently stopped the tape and discussed how they suspected the son of shoplifting and how they did not trust his promises. The fact that the son's seeming compliance elicited this concern was completely hidden in the session transcript. This conjunction of an action by the son and a hidden response by both parents may have led to some affective confusion in the session. The therapist, for example, expressed considerable confusion about session interactions in his reconnaissance material proximal to this stop point. The very important reaction and information consensually expressed by the parents did not exist in the session material at all. This example illustrates how a theory about latent contents may contribute to deepening our understanding of the various situations that arise in a systems-oriented therapy.

\section{Nonconsensus Points}

Nonconsensus points also merit inspection in that these times offer insights into how individuals see events of the session that are not noticed by others. Occasionally something considered very important by an individual received little or no commentary in the session by anyone else. Time Six in the Appendix, for example, was seen as significant by the son who expressed disagreement with what he perceived to be his father's expectation that the son be enthusiastic about school. Interestingly, the Time-Five video transcript reveals that father actually did not indicate that the son should be enthusiastic. Rather, the transcript shows the father saying that he would be content with the son getting to school on time and just passing grades. The power of the reconnaissance approach is that it allows for this type of individual perspective while keeping it tied directly to important process in the family and therapy systems.

\section{DISCUSSION}

This article has outlined a grounded, naturalistic method for examining the structure of the multiple interpretations of session events that coexist among family therapy participants. We have delineated some of the properties of video reconnaissance data and outlined some of their implications for assessing participant interpretation. The video reconnaissance approach offers a highly productive bird's-eye view of the topography of meanings across the span of a family session.

Several observations about the results are notable. First, types of consensus included content, location, both, neither, or various admixtures, such as a focus on the same event but with differing interpretations of event significance. Understanding 
these differences might be useful in accessing conversation with participants about their interpretations of session events.

Second, both active parents and therapists interpreted small details in terms of larger family issues. This effort was reflected in more frequent stops, in more extended commentary during the reconnaissance interview, and, often, in higher levels of agreement with each other on overall stop-point locations in the session. These findings are consistent with research showing that a finer level of processing often is required when there is some ambiguity about what actually is happening in a sequence (e.g., Ginsburg \& Smith, 1993; Newtson, Enquist, \& Bois, 1977). Of course, another way to handle ambiguity is to tune out details, such as is commonly observed among children who often are the identified patients in family therapy. In this study, the children tended to stop the tape less frequently during the reconnaissance and their comments tended to be sparse and directly to the affective point.

Finally, in contrast to transcript material which rarely hinted at how participants might be attending to the larger structure of the session, the reconnaissance material suggests that participants were continuously responding to what was happening, from their perspective, in the past few minutes. Most reactions in the review sessions centered on comments about other therapy participants, but participants also had selfreflective reactions. For example, the son in the Appendix, commended "I should have been talking here" at a consensus point, while his mother commented during her own review that she talked too much in sessions.

\section{Theoretical Implications}

Video reconnaissance is a retrospective research tool for accessing elements of the ongoing interpretive ecology of events during family therapy. This ecology consists both of actual physical actions and ongoing subjective perceptions and interpretations, including those in memory that extend beyond the time boundaries of a session (Trierweiler \& Donovan, 1994; Trierweiler $\&$ Stricker, 1998). Because human interactions largely are lost in time, interpretation usually occurs in memory (Miller \& J ohnson-Laird, 1976). Video reconnaissance seems to assist memory by eliciting thoughts about events during and after sessions that might otherwise not be recalled. This "third-party perspective" captures an important aspect of the reality of therapy sessions that has yet to be documented in the research literature.

Tothe extent that future implementations of the procedure yield results similar to this study, video reconnaissance has a potential for contributing to our understanding of family therapy in several ways. First, it has long been recognized that content and process are intertwined (Greenberg, 1986). The reconnaissance approach places particular value on session content and suggests that very interesting information can be obtained with careful inquiry into individual interpretations of specific events in therapy. Video reconnaissance could be used in studies that explore how multiple interpretations impact session process.

Second, video reconnaissance al so operationalizes unique participant perspectives on events. These differing perspectives, including the therapist's, might offer standards against which to evaluate clinical formulations. It seems likely that differing perspectives exist in sessions whether or not they are accessed by a therapist and they may have an important impact on the course of events. The revelation of these perspectives could provide therapists with feedback and potentially useful insights into their own hypotheses.

Finally, this research suggests that the meaning of session events-and even the fact that particular events are noticed-can be both similar and different for different participants. Video reconnaissance offers clinicians one model for gaining greater

Fam. Proc., Vol. 39, Summer, 2000 
interpretive precision in understanding the ecology of session interactions and, potentially, in enhancing their interventions. We are not suggesting that such an expensive procedure be regularly used in family therapy. Additional research is needed to determine when videoreconnaissance might be most advantageous.

\section{Clinical Implications}

Reconnaissance comments and participant-identified consensus points suggest possible conversations with participants that clinicians and researchers might pursue to grasp the hidden realities of therapy process. Such possible conversations exist, in theory, in any interaction, but are rarely looked at. Therapists might open up new sources of information, avenues for exploration, or new hypotheses by seeking the unrevealed or "unsaid" interpretations surrounding specific events in the therapy. Clinicians could compare their own hypotheses about the therapeutic process against those of the family participants and various family members' viewpoints and interpretations against one another. Detail ed and local in-session inquiries may enhance the therapist's capacity to maintain what Anderson and Goolishian (1988) called "multipartiality" (taking in all views simultaneously). In the process, overall assessment, treatment, and the empirical groundedness of clinical conceptualization would benefit (see Trierweiler \& Stricker, 1998). In the case of Family Three, for example, the summary feedback from the video reconnaissance sessions provided the therapist with important new information about the nature of the miscommunications that occurred between the parents and their son. The information allowed the therapist to reconsider his own experience of confusion at key points in the session and to investigate more specifically each family member's reactions to session events. At the same time, the therapist could use information about how members converged and diverged at signifi- cant junctures as an additional source of hypotheses about unsaid conversations hidden in the therapy process.

More broadly, the present research urges clinicians to consider how general issues in a family are linked to the immediate interactions that unfold in family work. The video reconnaissance approach provides a useful framework for reflective inquiry into such linkages even when the procedure itself is not implemented. It might, for example, be useful for clinicians frequently to explore which particular events in a session are seen as significant by each family member, and each individual's explanation for selecting particular moments as being important.

There are additional clinical impacts stemming from the use of videotape playback in the reconnaissance method. Video review has been shown to contribute positively to psychotherapy outcome (Alger, 1969, 1976). It can lead individuals to see aspects of their behavior previously out of their awareness and provide the opportunity to take greater responsibility for themselves (Alger, 1969, 1976; Alger \& Hogan, 1969). Playback also may stimulate the therapist and clients to be aware of a feeling from the original session that can now be articulated more directly. Or, there may be recognition of a behavior in the session that was not seen at the time. In observing the therapist actively soliciting individual interpretations and reactions, family members can learn how they too might begin to acknowledge multiple perspectives among themselves.

\section{Reliability and Validity Issues}

Elliott (1986) has offered an extended review of the reliability and validity issues associated with video-cued recall procedures similar to video reconnaissance. Different issues apply depending on researchers' objectives-such as attempting to represent experience as it happened versus retrospective interpretations of prior experience. One concern is the reactivity of videotaping. 
Although being taped was an unusual event for most of the families in this study, none of the participants, including therapists, re ported that the taped sessions under review were dramatically different than ongoing work. I nterpretations generated by the procedure were directly grounded in session material. Thus, although we cannot say that video reconnaissance directly represents an individual's memory, the results are relevant and informative in understanding the session process. In this sense, the content reference model is a virtual model for the true events of the session.

Another issue that warrants comment has to do with the extent to which remembered material actually corresponds to ongoing interpretations, or is influenced by the distortions of memory, even in the face of the rich cues afforded by the video procedure (Hill, O'Grady, Balenger, et al., 1994). Our work suggests that sometimes participants knew well what was going on during the session because of its salience, and sometimes they did not. Thus, although such reliability and validity questions make sense when the procedure is considered primarily as access to past experience, they are less relevant to the exploratory yield of the procedure. An open, naturalistic stance seems to be a requirement for examining how interpersonal events are interpreted in context (Gottman, 1993). To the extent that all memories of social events are actually combinations of remembrances and reflective interpretation (Rennie, 1992), video reconnaissance is ecologically representative and sheds light on key issues of shared (or consensual) meaning in the family interaction context.

Most would agree that family interactions and family therapy are complicated. Yet, we have limited access to actual interactions and, then, only to those available within the constraints of the therapy setting, which is increasingly timelimited. Local complexities are often ignored to the detriment of our clients (Trierweiler \& Stricker, 1998). One can only imagine how informative it would Fam. Proc., Vol. 39, Summer, 2000 be to have complete stop-point displays and content reference models for an extended therapy. How many ongoing therapist interpretations would change under such circumstances, and how much better would interventions be grounded in actual client experience? We need stronger descriptive models for analyzing the interpretive realities of family sessions. Additional research, both with the methodology and with the perspective on interpersonal interpretation embodied in this strategy, may illuminate more general issues concerning the nature of human interpretation of interpersonal and relationship phenomena.

\section{REFERENCES}

Alexander, J .F., Barton, C., Schiavo, R.S., \& Parsons, B.V. (1976). Systems-behavioral intervention with families of delinquents: Therapeutic characteristics, family behavior, and outcome. J ournal of Consulting and Clinical Psychol ogy 44: 656-664.

Alger, I. (1969). Therapeutic use of videotape playback. J ournal of Nervous and Mental Disease 48: 430-436.

Alger, I . (1976). I ntegrating immediate videoplayback in family therapy (pp. 530-547). In P.J . Guerin (ed.), Family therapy: Theory and practice New York: Gardner Press.

Alger, I., \& Hogan, P. (1969). Enduring effects of videotape playback experience on family and marital relationships. American J ournal of Orthopsychiatry 39: 86-98.

Anderson, H., \& Goolishian, H.A. (1988). Human systems as linguistic systems: Preliminary and evolving ideas about the implications for clinical theory. Family Process 27: 371-393.

Bavelas, J.B. (1984). On "naturalistic" family research. Family Process 23: 337-341.

Bloom, B.S. (1954). The thought process of students in discussion (pp. 23-46). In S.J . French (ed.), Accent on teaching: Experiments in general education. New York: Harper \& Row.

Elliott, R. (1986). Interpersonal process recall (IPR) as a psychotherapy process research method (pp. 503-527). In L.S. Greenberg \& W.M. Pinsof (eds.), The psychotherapeutic process: A research handbook. New York: Guilford Press.

Elliott, R., Shapiro, D.A., Firth-Cozens, J., \& 
Stiles, W.B. (1994). Comprehensive process analysis of insight events in cognitive-behavioral and psychodynamic-interpersonal psychotherapies. J ournal of Counseling Psychology 41: 449-463.

Ericsson, K.A., \& Simon, H.A. (1984/1993). Protocol analysis: Verbal reports as data. Cambridge, MA: MIT Press.

Fichten, C.S. (1984). See it from my point of view: Videotape and attributions in happy and distressed couples. J ournal of Social and Clinical Psychol ogy 2: 125-142.

Ginsburg, G.P., \& Smith, D.L. (1993). Exploration of the detectable structure of social episodes: The parsing of interaction specimens. Ecological Psychol ogy 5: 195-233.

Gottman, J .M. (1993). A theory of marital dissolution and stability. J ournal of Family Psychology 7: 57-75.

Greenberg, L.S. (1986). Change process research. J ournal of Consulting and Clinical Psychology 54: 4-9.

Gurman, A.S., Kniskern, D.P., \& Pinsof, W.M. (1986). Research on the process and outcome of marital and family therapy (pp. 565-624). In S. Bergin \& A. Garfield (eds.), Handbook of psychotherapy and behavior change (3rd ed.). New York: J onn Wiley \& Sons.

Halford, W.K., \& Sanders, M.R. (1988). Assessment of cognitive self-statements during marital problem solving: A comparison of two methods. Cognitive Research and Therapy 12: 515-530.

Heatherington, L. (1989). Toward more meaningful clinical research: Taking context into account in coding psychotherapy interaction. Psychotherapy 26: 436-447.

Heatherington, L., Friedlander, M.L., J ohnson, B., Buchanan, R.M., Burke, L.E., \& Shaw, D.M. (1998). Assessing individual family members' constructions of family problems. Family Process 37: 167-187.

Hill, C.E., O'Grady, K.E., Balenger, V., Busse, W., Falk, D.R., Hill, M., Rios, P., \& Taffe, R. (1994). Methodological examination of videotapeassisted reviews in brief therapy: Helpfulness ratings, therapist intentions, dient reactions, mood, and session evaluation. J ournal of Counseling Psychology 41: 236-247.

Hogan, P., \& Alger, I. (1969). The impact of videotaperecording on insight in group therapy.
International J ournal of Group Therapy 19: 158-164.

Kagan, N.I., \& Kagan, H. (1990). IPR-A validated model for the 1990s and beyond. The Counseling Psychologist 18: 436-440.

Kagan, N.I ., Krathwohl, D.R., \& Miller, R. (1963). Stimulated recall in therapy using video tape-A case study. J ournal of Counseling Psychol ogy 10: 237-243.

Kagan, N.I., \& Schauble, P.G. (1969). Affect simulation in interpersonal process recall. J ournal of Counseling Psychology 16: 309-313.

Kiesler, D.J . (1986). Foreword (pp. vii-xi). In L.S. Greenberg \& W.M. Pinsof (eds.), The psychotherapeutic process: A research handbook. New York: Guilford Press.

Knudson, R.M., Sommers, A.A., \& Golding, S.L. (1980). Interpersonal perception and mode of resolution in marital conflict. J ournal of Personality and Social Psychol ogy 38: 751-763.

Llewelyn, S.P., Elliott, R., Shapiro, D.A., Hardy, G., \& Firth-Cozens, J . (1988). Client perceptions of significant events in prescriptive and exploratory periods of individual therapy. British J ournal of Clinical Psychology 27: 105-114.

Meichenbaum, D., \& Butler, L. (1980). Cognitive ethology: Assessing the streams of cognition and emotion (pp. 139-164). In K. Blankstein, P. Pliner, \& J . Polivy (eds.), Advances in thestudy of communication and affect: Assessment and modification of emotional behavior (Vol . 6). New York: Plenum Press.

Miles, M.B., \& Huberman, A.M. (1994). Qualitativedata analysis: A sourcebook of new methods (2nd ed.). Beverly Hills, CA: Sage Publications. Miller, G.A., \& J ohnson-Laird, P.N. (1976). Language and perception. Cambridge: Harvard University Press.

Newston, D., Enquist, G., \& Bois, J . (1977). The objective basis of behavior units. J ournal of Personal ity and Social Psychology 35: 847-862.

Pinsof, W. (1981). Family therapy process re search (pp. 699-741). In A.S. Gurman \& D.P. Kniskern (eds.), Handbook of family therapy. New York: Brunner/Mazel.

Pinsof, W.M. (1986). The process of family therapy: The development of the family therapist coding system (pp. 201-284). In L. Greenberg \& W.M. Pinsof (eds.), The psychotherapeutic process: A research handbook. New York: Guilford Press.

Pinsof, W.M. (1988). Strategies for the study of family therapy process (pp. 159-174). In L.C. 
Wynne (ed.), The state of the art in family therapy research: Controversies and recommendations. New York: Family Process Press.

Pinsof, W.M. (1989). A conceptual framework and methodological criteria for family therapy process research.J ournal of Consulting and Clinical Psychology 57: 53-59.

Pinsof, W.M., \& Catherall, D. (1986). Theintegrative psychotherapy alliance: Family, couple, and individual therapy scales. J ournal of Marital and Family Therapy 12: 137-152.

Postner, R.S., Guttman, H.A., Sigal, J J ., Epstein, N.B., \& Rakoff, V.M. (1971). Process and outcome in conjoint family therapy. Family Process 10: 451-473.

Pruchno, R. (1993a, August). (Chair), Research methods, what's hot, what's not: F amily perspectives-making sense of data from multiple family members. Symposium conducted at the meeting of theAmerican Psychol ogical Association, Toronto.

Pruchno, R. (1993b, August). Family mental health: Marital and parent-child consensus as predictor. In R. Pruchno (Chair), Research methods, what's hot, what's not: Family perspectives-making sense of data from multiple family members. Symposium conducted at the meeting of theAmerican Psychol ogical Association, Toronto.

Rennie, D.L. (1992). Qualitative analysis of the dient's experience of psychotherapy: Theunfolding of reflexivity (pp. 211-233). In S.G. Toukmanian \& D.L. Rennie (eds.), Psychotherapy process research: Paradigmatic and narrative approaches. Newbury Park CA: Sage Publications.

Rice, L., \& Greenberg, L. (eds.). (1984). Patterns of change New York: Guilford Press.

Sanders, M.R., \& Dadds, M.R. (1992). Children's and parents' cognitions about family interaction: An evaluation of video-mediated recall and thought listing procedures in the assessment of conduct-disordered children. J ournal of Clinical Child Psychology 21: 371-379.

Stricker, G., \& Trierweiler, S.J . (1995). The local dinical scientist: A bridge between science and practice American Psychologist 50: 995-1002.

Sullivan, H.S. (1954). The psychiatric interview. New York: W.W. Norton.

Trierweiler, S.J ., \& Donovan, C.M. (1994). Exploring the ecological foundations of memory in psychotherapy: Interpersonal affordance, perception, and recollection in real time. Clinical Psychology Review 14: 301-326.

Trierweiler, S.J ., \& Stricker, G. (1998). The scientific practice of professional psychology. New York: Plenum Press.

Watson, J .C., \& Rennie, D.L. (1994). Qualitative analysis of client's subjective experience of significant moments during the exploration of problematic reactions. J ournal of Counseling Psychology 4: 500-509.

Manuscript received December 21, 1998; final revision submitted November 29, 1999; accepted December 7, 1999.

Endnote: In producing the content reference models, text involving extraneous or repetitive content was removed from the reconnaissance material-as excerpted in the Appendix. The participants' own language was retained throughout and no language was added to a field, nor were statements reworded, except as needed to assure the confidentiality of the participants for this presentation. In order to examine the reliability of our data reduction procedure, field word counts were used to index the material retained. Research assistants with minimal training regularly were able to achieve percentage agreements above $90 \%$. Inspection of disagreements showed them to involve minor differences in thestandard applied in determining redundant material or not. At no point was the major focus on an individual's comments excluded. 


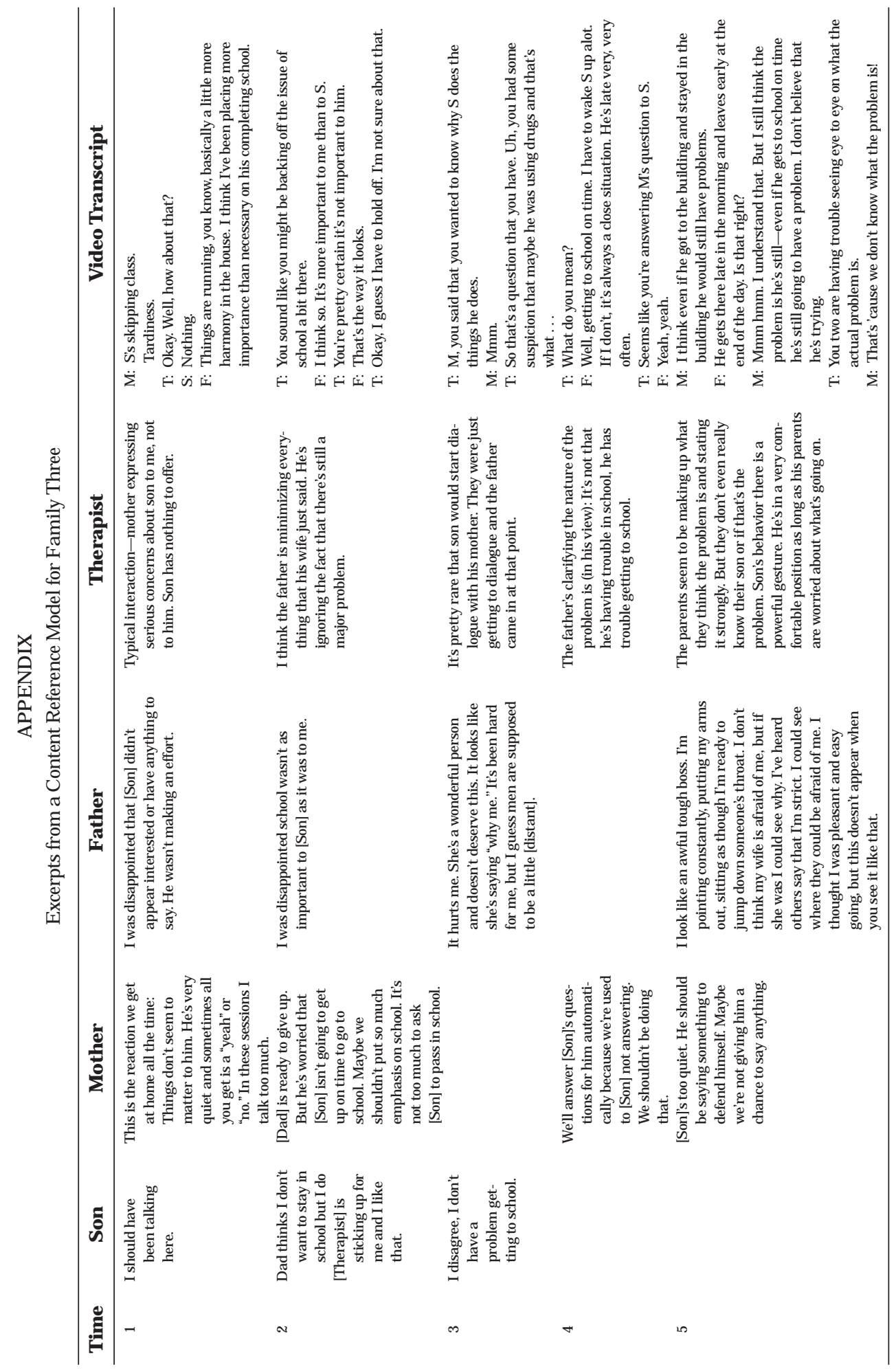




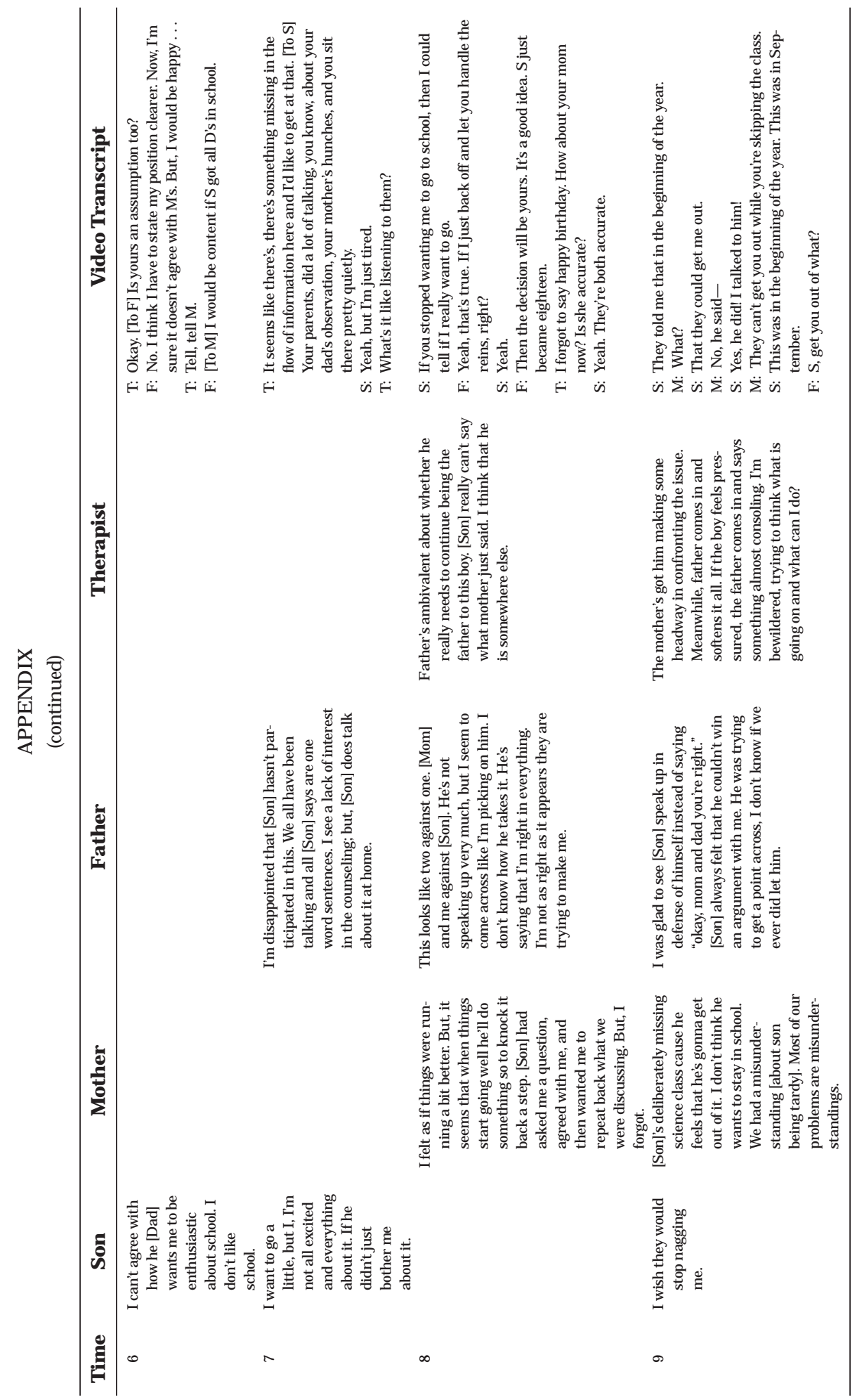

Fam. Proc., Vol. 39, Summer, 2000 